\title{
EVALUATING THE DISTANCE LEARNING IN THE PANDEMIC ERA: A CASE STUDY AT FINANCIAL EDUCATION AND TRAINING AGENCY MAKASSAR
}

\author{
Azwar Iskandar ${ }^{1}$, Achmat Subekan ${ }^{2}$ \\ ${ }^{1}$ Balai Diklat Keuangan Makassar, BPPK, Makassar, Indonesia \\ ${ }^{2}$ Pusdiklat Anggaran dan Perbendaharaan, BPPK, Bogor, Indonesia \\ 'azwar.iskandar@mail.com, ${ }^{2}$ achmatsubekan@mail.com
}

\begin{abstract}
The objectives of this research were to: (i) evaluate the trainees's satisfaction on trainers and training performance; (ii) evaluate learning gain or the improvement of trainees's skills, knowledge, and attitude after training; and (iii) know the significant obstacles that reduced the effectiveness of training. This study was conducted by using Kirkpatrick Evaluation Model through questionnaires, interviews, and descriptive statistics method. This research revealed that: (i) the overall aspect of the implementation evaluation assessed by participants was in Good category although it could not meet the level of participants' expectations. It could be seen from the ratio of the average total perception/reality and the average of important which were below $100 \%$. On the other hand, it was found that the trainers were been able to meet the participants' expectations with the category of Very Good; (ii) the results of the evaluation analysis at Level 2 (learning gain) indicated that most of the participants graduated with Good predicate and got an increased score. Thus, it could be asserted that the participants gained additional knowledge after attending the training; (iii) there were some obstacles faced by participants in attending the training although in general the evaluation results showed good results. In terms of administration, it was found that participants generally complained about inadequate internet quality in some areas. Meanwhile, based on the trainers aspect, it was revealed that participants generally gave suggestions for trainers to add case studies and to raise the latest issues in handling the problems related to training materials.
\end{abstract}

Keywords: training, distance learning, evaluation, Kirkpatrick, pandemic

\section{EVALUASI PELATIHAN JARAK JAUH DI MASA PENDEMI: STUDI KASUS BALAI DIKLAT KEUANGAN MAKASSAR}

\begin{abstract}
ABSTRAK
Penelitian ini dilaksanakan dengan tujuan untuk: (i) mengevaluasi kepuasan peserta pelatihan terhadap pengajar dan penyelenggaraan pelatihan; (ii) mengevaluasi learning gain atau peningkatan keterampilan, pengetahuan, dan sikap peserta setelah mengikuti pelatihan; dan (iii) mengetahui kendala signifikan yang dapat mengurangi efektifitas pelatihan. Dengan menggunakan Model Evaluasi Kirkpatrick melalui instrumen penelitian berupa kuesioner dan wawancara serta teknik analisis statistik deskriptif, penelitian ini menemukan bahwa: (i) keseluruhan aspek evaluasi penyelenggaraan dinilai oleh peserta dengan kategori Baik meskipun belum dapat memenuhi tingkat harapan dari peserta yang dapat dilihat dari rasio/perbandingan total rata-rata persepsi /kenyataan dan rata-rata kepentingan di bawah 100\%. Di sisi lain, aspek pengajar telah dapat memenuhi harapan dari peserta dimana keseluruhan tingkat kinerja pengajar sudah dinilai oleh peserta dan masuk ke dalam kategori Sangat Baik; (ii) hasil analisis evaluasi pada Level 2 (Learning Gain) menunjukkan bahwa sebagian besar peserta lulus dengan predikat Baik dan mendapatkan nilai naik/meningkat sehingga dapat dikatakan bahwa peserta telah mendapatkan tambahan ilmu pengetahuan (knowledge) setelah mengikuti pelatihan; (iii) meskipun secara umum hasil evaluasi menunjukkan hasil yang baik, masih tampak adanya beberapa kendala yang dihadapi oleh peserta dalam mengikuti pelatihan. Pada aspek penyelenggaraan, peserta pada umumnya mengeluhkan tentang kualitas jaringan internet yang tidak memadai di beberapa daerah. Sementara itu pada aspek pengajar, pada umumnya peserta memberi masukan kiranya para pengajar dapat memperbanyak studi kasus dan mengangkat isu-isu terkini dalam pengananan masalah terkait materi pelatihan.
\end{abstract}

Kata Kunci: pelatihan, jarak jauh, evaluasi, Kirkpatrick, pandemi

\begin{tabular}{|c|c|c|}
\hline Submitted & Accepted & Published \\
\hline 17 September 2020 & 04 November 2020 & 24 November 2020 \\
\hline
\end{tabular}

\begin{tabular}{|l|c|c|}
\hline Citation & $:$ & $\begin{array}{r}\text { Iskandar, A., \& Subekan, A. (2020). Evaluating the Distance Learning in the Pandemic Era A Case Study at Financial } \\
\text { Education and Training Agency Makassar. Jurnal PAJAR (Pendidikan dan Pengajaran), 4(6), 1206-1221. DOI : } \\
\text { http://dx.doi.org/10.33578/pjr.v4i6.8131. }\end{array}$ \\
\hline
\end{tabular}




\section{PENDAHULUAN}

Sebagai unit pelaksana pendidikan dan pelatihan (diklat) di lingkungan Kementerian Keuangan, Balai Diklat Keuangan (BDK) Makassar sebagai unit pelaksana teknis Badan Pendidikan dan Pelatihan Keuangan (BPPK) di daerah selalu berkomitmen untuk senantiasa menjaga dan meningkatkan kualitas pembelajaran yang diselenggarakan untuk mewujudkan pelayanan prima (Iskandar, 2019). Komitmen untuk menjaga kualitas pembelajaran BPPK dilakukan sejak tahapan perencanaan pembelajaran sampai dengan evaluasi pascapembelajaran. Perencanaan pembelajaran dilakukan dengan melakukan Analisis Kebutuhan Pembelajaran (AKP) dan menyusun Desain Pembelajaran serta validasi program pembelajaran secara intensif. Kualitas penyelenggaraan pembelajaran senantiasa dijaga dengan senantiasa memantau atau mengevaluasi kualitas pembelajaran berdasarkan survei kepada peserta selama pembelajaran berlangsung. Tahap terakhir adalah evaluasi pascapembelajaran yang bertujuan untuk mengetahui apakah pembelajaran yang diikuti mampu memberikan kontribusi terhadap peningkatan kinerja alumni peserta dan/atau kinerja organisasi (Iskandar dan Amriani, 2019).

Sebagai bentuk adaptasi terhadap perkembangan teknologi, fleksibilitas ruang pembelajaran (flexibility learning space), pertimbangan efektivitas dan efisiensi, kemudahan penerapan pembelajaran terintegrasi, BPPK mengembangkan pembelajaran dalam bentuk pelatihan jarak jauh sebagai alternatif pembelajaran di lingkungan BPPK. Pelatihan Jarak Jauh (Distance Learning) yang kemudian disingkat PJJ merupakan proses pembelajaran yang dilaksanakan di luar tempat penyelenggaraan pelatihan yang menekankan pada pembelajaran mandiri yang dikelola secara sistematik dan tidak terbatas oleh jarak dan waktu dengan menggunakan berbagai media pembelajaran (BPPK, 2020).

Dalam menghadapi kondisi pandemi Covid-19 saat ini, proses diklat dan pelatihan di lingkungan BPPK tidak dapat dilaksanakan sebagaimana biasanya. Kebijakan physical dan social distancing hingga Pembatasan Sosial Berskala Besar (PSBB) dari pemerintah untuk mengantisipasi penularan virus tersebut, mengharuskan masyarakat untuk tetap stay at home, bekerja, beribadah dan belajar dari rumah. Kondisi demikian menuntut lembaga pendidikan dan pelatihan, termasuk BPPK, untuk melakukan adaptasi dalam proses pembelajaran. Salah satu bentuk adaptasi tersebut adalah dengan penyelenggaraan pembelajaran secara jarak jauh, yaitu secara online atau daring. Pembelajaran daring atau pembelajaran jarak jauh ini bertujuan untuk memenuhi kebutuhan peningkatan dan pengembangan SDM di lingkungan Kementerian Keuangan melalui pemanfaatan teknologi dan informasi meski terkendala dengan pembatasan penyelenggaraan pelatihan seperti di masa pandemi saat ini.

PPJ di lingkungan BPPK dilaksanakan melalui sistem Kemenkeu Learning Centre (KLC) yang berbasis web (www.klc.kemenkeu.go.id) untuk sesi Non Tatap Muka dan aplikasi Zoom Virtual Meeting atau lainnya untuk sesi Tatap Muka serta aplikasi Google Form untuk sesi latihan, tugas, dan ujian. Model PJJ ini merupakan penggabungan model pembelajaran synchronous dan asynchronous. Model synchronous dalam PJJ ini dilakukan melalui aplikasi Zoom Virtual Meeting dimana peserta pelatihan dan pengajar/instruktur berinteraksi secara bersamaan melalui aplikasi tersebut (Narayana, 2016). Sementara model asynchronous dalam PJJ ini dilakukan melalui sistem KLC dimana pembelajaran berpusat pada peserta pelatihan dengan pendekatan belajar mandiri melalui pemanfaatan sumber belajar online yang diperlukan pada sistem tersebut.

Dalam melakukan evaluasi terhadap pelaksanaan diklat, termasuk PJJ, BDK Makassar menggunakan model evaluasi Kirkpatrick. Model evaluasi ini terdiri dari 4 level, dimana setiap level dalam model evaluasi ini mempengaruhi level berikutnya (Kirkpatrick, 2008). Keempat level evaluasi itu adalah: (1) Level 1 (Reaction), yaitu evaluasi yang mengukur bagaimana peserta 
bereaksi terhadap pembelajaran yang diikuti, atau dengan kata lain mengukur kepuasan peserta pembelajaran (customer satisfaction); (2) Level (Learning), yaitu evaluasi yang mengukur proses belajar dalam pembelajaran yakni terjadinya transfer pengetahuan (transfer of learning). Evaluasi pada level ini bertujuan untuk mengukur hasil belajar peserta, yang antara lain perubahan sikap, berkembangnya pengetahuan dan/atau peningkatan keterampilan; (3) Level 3 (Behavior), yaitu evaluasi yang bertujuan untuk mengetahui sejauh mana perubahan perilaku yang terjadi setelah peserta mengikuti pembelajaran; dan (4) Level 4 (Results), yaitu evaluasi untuk mengukur result atau hasil akhir yang terjadi setelah peserta mengikuti pembelajaran. Hasil akhir tersebut dapat berupa peningkatan produktivitas, peningkatan kualitas, penurunan biaya, penurunan tingkat kecelakaan kerja, peningkatan penjualan, penurunan tingkat keluarmasuk pegawai, dan meningkatnya keuntungan (Kirkpatrick, 2008).

Mengingat bahwa model pembelajaran jarak jauh ini merupakan sebuah adaptasi atau inovasi baru di lingkungan BPPK di masa transisi normal baru (new normal) di mana pelaksanaan pelatihan klasikal belum dapat dilaksanakan sebagaimana biasanya, penting untuk melakukan suatu kajian atau penelitian untuk melihat sejauh mana efektivitas dan kualitas pelaksanaan PJJ dengan melaksanakan evaluasi baik pada saat proses diklat berlangsung maupun setelah pelatihan telah selesai. Beberapa penelitian terdahulu telah mengkaji dan melakukan evaluasi terhadap pelaksanaan pelatihan jarak jauh. Septian (2020) melakukan evaluasi terhadap pelaksanaan PJJ dengan bantuan e-learning dan pengenalan media sosial Edmodo. Penelitian ini mememukan bahwa kegiatan PJJ ini dapat menambah pemahaman guru pamong dalam menggunakan media sosial Edmodo sebagai alat bantu PJJ serta bermanfaat sebagai media pembelajaran yang dilakukan di sekolah. Hayadin (2012) melakukan penelitian untuk mengetahui konteks, input, proses dan output penyelenggaraan diklat jarak jauh yang diselenggarakan oleh Kementerian Agama sejak tahun 2009. Penelitian ini menggunakan metode survei pada beberapa lokasi penelitian di Indonesia. Penelitian ini menyimpulkan bahwa penyelenggaraan diklat jarak jauh yang telah dilaksanakan sejak tahun 2009 pada beberapa balai diklat, telah memberikan kontribusi terhadap tiga hal, yaitu: a) meningkatkan jumlah peserta diklat; b) memberikan kompetensi TIK kepada widyaiswara dan staf balai diklat untuk menjadi tutor online dan administrator diklat jarak jauh; dan c) menyediakan Virtual Learning Environtment (VLE), hardware dan software dalam bentuk website internet dengan content yang mendukung pembelajaran jarak jauh. Selanjutnya, Sari (2020) juga melakukan evaluasi terhadap pelatihan jarak jauh kepada para guru dalam menggunakan aplikasi Google Form sebagai media pembelajaran jarak jauh. Hasil kajian ini menunjukkan bahwa peserta pelatihan memperoleh tambahan keterampilan dan dapat memahami prinsip-prinsip dalam pembuatan kuis secara online menggunakan aplikasi Google.

Meskipun beberapa penelitian tersebut di atas telah mencoba mengkaji dan mengevaluasi pelaksanaan pelatihan jarak jauh, akan tetapi penelitian-penelitian tersebut tidak mengkaji pelaksanaan pelatihan yang dilaksanakan secara khusus di masa pandemi seperti saat ini. Sejauh pengamatan penulis, penelitian yang dilakukan untuk mengevaluasi pelaksanaan pelatihan jarak jauh di masa pandemi, belum banyak dilakukan. Oleh karena itu, untuk mengisi gap tersebut, penelitian ini dilaksanakan dengan tujuan untuk :

1. mengevaluasi kepuasan peserta pelatihan terhadap pengajar dan penyelenggaraan PJJ;

2. mengevaluasi learning gain atau peningkatan keterampilan, pengetahuan, dan sikap peserta setelah mengikuti PJJ;

3. mengetahui kendala signifikan yang dapat mengurangi efektifitas pelaksanan PJJ.

Ruang lingkup penelitian hanya mencakup pengkajian terhadap kriteria evaluasi Model Kirkpatrick pada Level 1 (Reactions) dan Level 2 (Learning). Sementara kriteria evaluasi pada Level 3 (Behavior) dan Level 4 (Results) tidak termasuk dalam ruang lingkup kajian/evaluasi karena evaluasi pada level-level ini masih membutuhkan waktu (lag) dan hanya hanya dapat dilakukan pada waktu lebih dari 
enam bulan sampai 1 tahun ke depan (short term) atau bahkan dua sampai sepuluh tahun berikutnya (long term) (Iskandar, 2019). Penelitian ini dilakukan terhadap alumni dua Pelatihan Jarak Jauh (PJJ) yang telah diselenggarakan di BDK Makassar pada periode bulan Juli dan Agustus 2020, yaitu PJJ Pengelolaan Barang Milik Negara Bagi Pengguna dan PJJ Kertas Kerja Analisis Wajib Pajak. PJJ Pengelolaan Barang Milik Negara Bagi Pengguna diperuntukkan bagi Aparatur Sipil Negara di Lingkungan Kementerian Keuangan atau Kementerian/Lembaga yang memiliki tugas dan fungsi mengelola BMN di satuan kerjanya namun belum pernah mendapatkan pengetahuan dan skill yang dibutuhkan untuk memenuhi gap kompetensi terkait perencanaan kebutuhan BMN, penggunaan dan pemanfaatan $\mathrm{BMN}$, pengamanan dan pemeliharaan $\mathrm{BMN}$, pemindahtanganan dan penghapusan $\mathrm{BMN}$, penilaian $\mathrm{BMN}$, penatausahaan, Modul Persediaan, Modul Aset Tetap, dan Aplikasi SIMAN Pengguna Barang. Sedangkan PJJ Kertas Kerja Analisis Wajib Pajak diperuntukkan bagi Account Representative atau Pelaksana Seksi Bimbingan dan Pemeriksaan di lingkungan Direktorat Jenderal Pajak dalam rangka memberikan pemahaman, baik secara teori maupun praktik, mengenai penyusunan kertas kerja analisis secara terstruktur dan menemukan potensi Wajib Pajak dari aplikasi internal dan eksternal yang dapat digunakan sebagai bahan baku pemeriksaan.

\section{METODE PENELITIAN}

Penelitian ini menggunakan analisis kuantitatif dan kualitatif yang merupakan analisis yang didasarkan pada hubungan semantis antarvariabel yang diteliti (Sarwono, 2006). Sumber data yang digunakan berupa data primer dan sekunder. Data primer berupa data yang dihasilkan secara langsung dari responden, berupa jawaban pertanyaan pada lembar kuesioner dan wawancara dengan alumni pelatihan sebagai responden. Sedangkan data sekunder berupa data penunjang yang diperoleh dan tersedia pada instansi terkait seperti Kerangka Acuan Program (KAP) Diklat, Garis-Garis Besar Program Pembelajaran (GBPP), hasil Identikasi Kebutuhan Diklat (IKD), dan Laporan Penyelenggaran Pelatihan Seksi Evaluasi dan Informasi Balai Diklat Keuangan Makassar. Variabel-variabel penelitian yang digunakan sebagaimana ditunjukkan pada Tabel 1 berikut.

Tabel 1. Variabel Penelitian

\begin{tabular}{|c|c|c|c|}
\hline Variabel & Definisi & Indikator & $\begin{array}{c}\text { Pengukuran dan } \\
\text { Instrumen Evaluasi }\end{array}$ \\
\hline $\begin{array}{l}\text { Level } 1 \\
\text { (Reaction) }\end{array}$ & $\begin{array}{l}\text { Mengukur dan } \\
\text { mengevaluasi bagaimana } \\
\text { peserta diklat bereaksi } \\
\text { dan merasa puas terhadap } \\
\text { diklat yang diikuti } \\
\text { (costumer satisfaction). }\end{array}$ & $\begin{array}{ll}\text { 1. } & \text { Nilai Evaluasi } \\
& \text { Penyelenggaran } \\
\text { 2. } & \text { Nilai Evaluasi Pengajar }\end{array}$ & $\begin{array}{l}\text { Menganalisis hasil kuesioner untuk: } \\
\text { 1. Evaluasi Penyelenggaran } \\
\text { 2. Evaluasi Pengajar } \\
\text { Seluruh item pertanyaan dalam } \\
\text { kuesioner tersebut menggunakan } \\
\text { pengukuran skala Likert dengan } \\
\text { alternatif jawaban yang disediakan } \\
\text { yaitu : Tidak Baik (1), Kurang Baik } \\
\text { (2), Cukup (3), Baik (4) dan } \\
\text { Sangat Baik (5). }\end{array}$ \\
\hline $\begin{array}{l}\text { Level } 2 \\
\text { (Learning) }\end{array}$ & $\begin{array}{l}\text { Mengukur dan } \\
\text { mengevaluasi bagaimana } \\
\text { peserta diklat mampu } \\
\text { merubah sikap, } \\
\text { pengetahuan, } \\
\text { keterampilannya sebagai } \\
\text { hasil dari mengikuti } \\
\text { program diklat. }\end{array}$ & $\begin{array}{l}\text { Nilai Ujian Pre Test, Post } \\
\text { Test dan Ujian (Learning } \\
\text { Gain). }\end{array}$ & $\begin{array}{l}\text { Menganalisis hasil Pre Test, Post Test } \\
\text { dan Ujian (Learning Gain). }\end{array}$ \\
\hline
\end{tabular}


Jurnal PAJAR (Pendidikan dan Pengajaran)

Volume 4 Nomor 6 November 2020 | ISSN Cetak : 2580 - 8435 | ISSN Online : 2614 - 1337

DOI : http://dx.doi.org/10.33578/pjr.v4i6.8131

Populasi dalam penelitian berjumlah 49 orang yang terdiri dari 20 orang alumni PJJ Pengelolaan Barang Milik Negara Bagi Pengguna dan 29 orang alumni PJJ Kertas Kerja Analisis Wajib Pajak. Adapun sampel dalam evaluasi ini diambil dengan menggunakan teknik saturation sampling (sampel jenuh). Teknik ini dipakai jika semua anggota populasi digunakan sebagai sampel, hal ini dilakukan bila jumlah populasi relatif kecil atau penelitian ingin membuat generalisasi dengan kesalahan yang sangat kecil (Sugiyono, 2005). Berdasarkan hal tersebut, maka jumlah sampel penelitian ditetapkan juga sebanyak 49 orang.

Data kuesioner untuk evaluasi Level 1 (Reaction) yang berhasil dikumpulkan kemudian dianalisis dengan metode statistika deskriptif. Penentuan peringkat indeks penilaian menggunakan PER- 001/PP/2014 tentang Pedoman Evaluasi dan Rekomendasi Diklat di Lingkungan Kementerian Keuangan (BPPK, 2014) dengan range sebagai berikut :

a. $1 \leq$ Nilai rata-rata keseluruhan $<1.8$, kategori

Tidak Baik; b. $1.8 \leq$ Nilai rata-rata keseluruhan $<2.6$, kategori Kurang Baik;

c. $2.6 \leq$ Nilai rata-rata keseluruhan $<3.4$, kategori Cukup;

d. $3.4 \leq$ Nilai rata-rata keseluruhan $<4.2$, kategori Baik;

e. $4.2 \leq$ Nilai rata-rata keseluruhan $<5$, kategori Sangat Baik.

Metode/teknik statistik deskriptif yang digunakan adalah teknik dalam bentuk distribusi frekuensi untuk mengetahui frekuensi penyebaran jawaban pada setiap item pertanyaan. Data yang yang terkumpul, kemudian ditabulasikan dan ditampilkan dilengkapi dengan rata-rata dan persentase jawaban pada tiap-tiap butir pertanyaan yang dipilih responden.

Selain dengan metode/teknik statistik deskriptif, penelitian ini juga menggunakan metode Importance Performance Analysis (IPA) untuk membandingkan antara kinerja/kenyataan (sumbu X) dengan kepentingan/harapan (sumbu Y). Hasil perbandingan tersebut akan diinterpretasikan dengan matriks kepentingan kinerja sebagai berikut.

Tabel 2. Matriks Kepentingan Kinerja

\begin{tabular}{|c|c|c|c|}
\hline & \multicolumn{2}{|c|}{ Persepsi (X) } \\
\hline & & Rendah & Tinggi \\
\hline $\begin{array}{c}\text { Kepentingan/ } \\
\text { Ekspektasi/ } \\
\text { Harapan } \\
\text { (Y) }\end{array}$ & Tinggi & $\begin{array}{c}\text { Kuadran II } \\
\text { (kepentingan tinggi; kinerja rendah) } \\
\text { PERLU DIPERBAIKI } \\
\text { Kuadran IV } \\
\text { (kepentingan rendah, kinerja rendah) } \\
\text { TIDAK MENJADI PRIORITAS }\end{array}$ & $\begin{array}{c}\text { Kuadaran I } \\
\text { (kepentingan tinggi, kinerja tinggi) } \\
\text { PERLU DIPERTAHANKAN } \\
\text { Kuadran III } \\
\text { (kepentingan rendah, kinerja tinggi) } \\
\text { SUDAH BAIK, TIDAK PERLU } \\
\text { DIPRIORITASKAN DAN } \\
\text { DITINGKATKAN }\end{array}$ \\
\hline
\end{tabular}

Sumber: Peraturan Kepala BPPK Nomor PER-5/PP/2017 tentang Pedoman Evaluasi Pembelajaran di Lingkungan Kementerian Keuangan (BPPK, 2017)

\section{HASIL DAN PEMBAHASAN Response Rate}

Jumlah responden yang ditetapkan sebagai sampel penelitian ini berjumlah 49 orang. Kuesioner penelitian telah dikirim secara online kepada seluruh responden menggunakan perangkat Google Forms. Hingga batas akhir pengembalian kuesioner, jumlah responden yang mengembalikan kuesioner dalam keadaan terisi lengkap sebanyak 48 orang. Hal ini berarti tingkat pengembalian total kuesioner (response rate) hanya mencapai $97.9 \%$ dari jumlah sampel yang ditetapkan. Meskipun response rate tidak mencapai $100 \%$, penelitian tetap dapat dilanjutkan ke tahapan analisis. Hartono (2011) menyebutkan bahwa response rate tidak harus mencapai $100 \%$, 
namun akan semakin baik apabila tingkat respon semakin tinggi. Bahkan kuesioner yang dikirimkan lewat media (seperti pos atau e-mail) dengan tingkat respon sebesar $30 \%$ sudah dapat dikatakan memadai. Terhadap kuesioner yang terisi tersebut kemudian dilakukan tabulasi, dilanjutkan dengan deskripsi dan klasifikasi responden berdasarkan umur dan pendidikan serta pengolahan data.

\section{Karakteristik Responden}

Penyajian data karakteristik responden bertujuan untuk mengenal ciri-ciri khusus yang dimiliki responden sehingga dapat membantu atau memudahkan dalam melakukan analisis. Karakteristik responden berdasarkan umur dan pendidikan terakhir untuk masing-masing responden, diuraikan sebagai berikut :

\section{Karakteristik Responden Berdasarkan Umur}

Karakteristik responden berdasarkan umur sebagaimana pada Tabel 3 berikut :

Tabel 3. Responden Berdasarkan Umur

\begin{tabular}{ccccc}
\hline Umur (tahun) & \multicolumn{2}{c}{$\begin{array}{c}\text { PJJ Pengelolaan } \\
\text { Barang Milik Negara } \\
\text { Bagi Pengguna }\end{array}$} & \multicolumn{2}{c}{$\begin{array}{c}\text { PJJ Kertas Kerja } \\
\text { Analisis Wajib Pajak }\end{array}$} \\
\cline { 2 - 5 } & $\begin{array}{c}\text { Jumlah } \\
\text { (org) }\end{array}$ & $\begin{array}{c}\text { Persentase } \\
(\%)\end{array}$ & $\begin{array}{c}\text { Jumlah } \\
\text { (org) }\end{array}$ & $\begin{array}{c}\text { Persentase } \\
(\%)\end{array}$ \\
\hline $20-25$ & 19 & 95.00 & 1 & 3.45 \\
$26-30$ & 0 & 0.00 & 11 & 37.93 \\
$31-35$ & 0 & 0.00 & 16 & 55.17 \\
$36-40$ & 1 & 5.00 & 1 & 3.45 \\
Jumlah & $\mathbf{2 0}$ & $\mathbf{1 0 0 . 0 0}$ & $\mathbf{2 9}$ & $\mathbf{1 0 0 . 0 0}$ \\
\hline \multicolumn{5}{c}{ Sumber : Data primer (diolah) }
\end{tabular}

Berdasarkan Tabel 3 di atas, responden dalam kegiatan evaluasi ini berdasarkan umur sebagian besar alumni adalah berumur di antara 20-25 tahun (berjumlah 19 orang atau $95.00 \%$ ) pada PJJ Pengelolaan Barang Milik Negara Bagi Pengguna dan berumur di antara 31-35 tahun (berjumlah 16 orang atau $55.17 \%$ ) pada PJJ Kertas Kerja Analisis Wajib Pajak. Hal ini berarti bahwa pelaksanaan PJJ yang memanfaatkan perangkat teknologi dan informasi seharusnya tidak menjadi kendala teknis bagi para peserta dalam mengikuti pelatihan dan pembelajaran karena peserta sebagai responden berumur relatif muda dan dapat menggunakan perangkat teknologi seperti internet, video conference, dan lainnya.

\section{Karakteristik Responden Berdasarkan Pendidikan Terakhir}

Karakteristik responden berdasarkan pendidikan terakhir sebagaimana pada Tabel 4 berikut :

Tabel 4. Responden Berdasarkan Pendidikan Terakhir

\begin{tabular}{ccccc}
\hline Pendidikan Terakhir & $\begin{array}{c}\text { PJJ Pengelolaan Barang } \\
\text { Milik Negara Bagi Pengguna }\end{array}$ & \multicolumn{2}{c}{$\begin{array}{c}\text { PJJ Kertas Kerja Analisis Wajib } \\
\text { Pajak }\end{array}$} \\
\cline { 2 - 5 } & $\begin{array}{c}\text { Jumlah } \\
\text { (org) }\end{array}$ & $\begin{array}{c}\text { Persentase } \\
(\boldsymbol{\%})\end{array}$ & $\begin{array}{c}\text { Jumlah } \\
(\text { org) }\end{array}$ & Persentase (\%) \\
\hline SMA sederajat & 1 & 5.00 & 0 & 0.00 \\
Diploma I & 14 & 70.00 & 4 & 13.79 \\
Diploma III & 5 & 25.00 & 8 & 27.59 \\
Starata Satu (S1) & 0 & 0.00 & 17 & 58.62 \\
Jumlah & $\mathbf{2 0}$ & $\mathbf{1 0 0 . 0 0}$ & $\mathbf{2 9}$ & $\mathbf{1 0 0 . 0 0}$ \\
\hline \multicolumn{5}{c}{}
\end{tabular}


Berdasarkan Tabel 4 di atas, responden dalam penelitian ini berdasarkan pendidikan terakhir, sebagian besar alumni memiliki pendidikan terakhir Diploma I yaitu sebanyak 14 orang atau $70.00 \%$ pada PJJ Pengelolaan Barang Milik Negara Bagi Pengguna dan memiliki pendidikan terakhir Starata Satu (S1)/Diploma IV (DIV) yaitu sebanyak 17 orang atau $58.62 \%$ ) pada PJJ Kertas Kerja Analisis Wajib Pajak. Hal ini berarti bahwa pelaksananaan PJJ yang memanfaatkan perangka informasi dan teknologi seharusnya juga tidak menjadi kendala teknis bagi para peserta dalam mengikuti pelatihan dan pembelajaran secara online atau jarak jauh.

\section{Analisis Evaluasi Model Kirkpatrick Level 1 (Reaction)}

Pedoman yang digunakan dalam melaksanakan kegiatan evaluasi pembelajaran adalah Peraturan Kepala BPPK Nomor PER5/PP/2017 tentang Pedoman Evaluasi Pembelajaran di Lingkungan Kementerian Keuangan dan KEP-82/PP/2020 tentang Panduan Penyelenggaraan Pelatihan Jarak Jauh (Distance Learning) di Lingkungan Badan Pendidikan dan Pelatihan Keuangan. Aspek yang dievaluasi yakni evaluasi atas peserta dan evaluasi atas pengajar dan penyelenggaraan.

\section{Hasil Analisis Statistik Deskriptif}

Hasil evaluasi tentang pemenuhan kepuasan peserta pelatihan terhadap pengajar dan penyelenggaraan pelatihan melalui kegiatan survei (kuesioner) dan evaluasi tatap muka (wawancara) adalah sebagai berikut:

Tabel 5. Skor Rata-Rata Komponen Evaluasi

\begin{tabular}{|c|c|c|c|c|c|c|c|}
\hline \multirow[t]{2}{*}{ No } & \multirow[t]{2}{*}{ Butir } & \multicolumn{3}{|c|}{$\begin{array}{c}\text { PJJ Pengelolaan Barang Milik Negara } \\
\text { Bagi Pengguna }\end{array}$} & \multicolumn{3}{|c|}{$\begin{array}{c}\text { PJJ Kertas Kerja Analisis Wajib } \\
\text { Pajak }\end{array}$} \\
\hline & & $\begin{array}{c}\text { Rata-Rata } \\
\text { Kepenting } \\
\text { an }\end{array}$ & $\begin{array}{c}\text { Rata-Rata } \\
\text { Persepsi } \\
\text { /Kenyataan }\end{array}$ & Kategori & $\begin{array}{c}\text { Rata-Rata } \\
\text { Kepenting } \\
\text { an }\end{array}$ & $\begin{array}{c}\text { Rata-Rata } \\
\text { Persepsi } \\
\text { /Kenyataa } \\
\text { n }\end{array}$ & Kategori \\
\hline (1) & (2) & (3) & (4) & (5) & (6) & (7) & $(9)$ \\
\hline \multicolumn{8}{|c|}{ PENYELENGGARAAN } \\
\hline 1 & $\begin{array}{l}\text { Kesesuaian } \\
\text { materi } \\
\text { pembelajaran } \\
\text { dengan } \\
\text { harapan/kebutu } \\
\text { han peserta }\end{array}$ & 4.55 & 4.50 & Sangat Baik & 4.36 & 4.36 & $\begin{array}{l}\text { Sangat } \\
\text { Baik }\end{array}$ \\
\hline 2 & $\begin{array}{l}\text { Bahan ajar } \\
\text { mudah } \\
\text { dipahami }\end{array}$ & 4.55 & 4.25 & Sangat Baik & 4.18 & 4.18 & Baik \\
\hline 3 & $\begin{array}{l}\text { Kesesuaian } \\
\text { metode } \\
\text { pembelajaran } \\
\text { dengan materi } \\
\text { Pelatihan Jarak } \\
\text { Jauh }\end{array}$ & 4.05 & 3.75 & Baik & 4.14 & 3.96 & Baik \\
\hline 4 & $\begin{array}{l}\text { Ketercukupan } \\
\text { waktu } \\
\text { penyelenggaraa } \\
\text { n Pelatihan } \\
\text { Jarak Jauh } \\
\text { dengan jumlah }\end{array}$ & 4.30 & 3.85 & Baik & 4.07 & 3.96 & Baik \\
\hline
\end{tabular}


Jurnal PAJAR (Pendidikan dan Pengajaran)

Volume 4 Nomor 6 November 2020 | ISSN Cetak : 2580 - 8435 | ISSN Online : 2614 - 1337

DOI : http://dx.doi.org/10.33578/pjr.v4i6.8131

\begin{tabular}{|c|c|c|c|c|c|c|c|}
\hline & $\begin{array}{l}\text { materi yang } \\
\text { diberikan }\end{array}$ & & & & & & \\
\hline 5 & $\begin{array}{l}\text { Kesigapan } \\
\text { penyelenggara } \\
\text { dalam melayani } \\
\text { peserta selama } \\
\text { proses Pelatihan } \\
\text { Jarak Jauh }\end{array}$ & 4.70 & 4.70 & Sangat Baik & 4.36 & 4.54 & $\begin{array}{l}\text { Sangat } \\
\text { Baik }\end{array}$ \\
\hline 6 & $\begin{array}{l}\text { Ketercukupan } \\
\text { waktu dalam } \\
\text { mengerjakan } \\
\text { penugasan, } \\
\text { kuis, atau ujian }\end{array}$ & 4.50 & 4.30 & Sangat Baik & 4.04 & 3.79 & Baik \\
\hline 7 & $\begin{array}{l}\text { Fasilitas } \\
\text { Pelatihan Jarak } \\
\text { Jauh mudah } \\
\text { diakses }\end{array}$ & 4.20 & 3.70 & Baik & 4.21 & 3.93 & Baik \\
\hline 8 & $\begin{array}{l}\text { Fasilitas } \\
\text { Pelatihan Jarak } \\
\text { Jauh mudah } \\
\text { digunakan } \\
\text { Rata-rata }\end{array}$ & 4.10 & 3.90 & Baik & 4.21 & 4.00 & Baik \\
\hline & Rata-rata & 4.37 & 4.12 & Baik & 4.20 & 4.09 & Baik \\
\hline \multicolumn{8}{|c|}{ PENGAJAR } \\
\hline No & $\begin{array}{l}\text { Pengajar } \\
\text { (Mata } \\
\text { Pelajaran) }\end{array}$ & $\begin{array}{l}\text { Rata-Rata } \\
\text { Harapan }\end{array}$ & $\begin{array}{l}\text { Rata-Rata } \\
\text { Persepsi } \\
\text { Kenyataan }\end{array}$ & Kategori & $\begin{array}{c}\text { Rata-Rata } \\
\text { Harapan }\end{array}$ & $\begin{array}{c}\text { Rata-Rata } \\
\text { Persepsi } \\
\text { Kenyataa } \\
\text { n } \\
\end{array}$ & Kategori \\
\hline 1 & A & 4.65 & 4.70 & Sangat Baik & 4.54 & 4.54 & $\begin{array}{l}\text { Sangat } \\
\text { Baik }\end{array}$ \\
\hline 2 & B & 4.70 & 4.50 & Sangat Baik & 4.46 & 4.50 & $\begin{array}{l}\text { Sangat } \\
\text { Baik }\end{array}$ \\
\hline 3 & $\mathrm{C}$ & 4.65 & 4.75 & Sangat Baik & 4.46 & 4.54 & $\begin{array}{l}\text { Sangat } \\
\text { Baik }\end{array}$ \\
\hline 4 & $\mathrm{D}$ & 4.65 & 4.70 & Sangat Baik & 4.50 & 4.50 & $\begin{array}{l}\text { Sangat } \\
\text { Baik }\end{array}$ \\
\hline 5 & E & 4.65 & 4.75 & Sangat Baik & 4.43 & 4.50 & $\begin{array}{l}\text { Sangat } \\
\text { Baik }\end{array}$ \\
\hline 6 & $\mathrm{~F}$ & 4.65 & 4.70 & Sangat Baik & 4.43 & 4.46 & $\begin{array}{l}\text { Sangat } \\
\text { Baik }\end{array}$ \\
\hline 7 & G & 4.65 & 4.75 & Sangat Baik & 4.50 & 4.50 & $\begin{array}{l}\text { Sangat } \\
\text { Baik }\end{array}$ \\
\hline 8 & $\mathrm{H}$ & 4.55 & 4.60 & Sangat Baik & 4.43 & 4.46 & $\begin{array}{l}\text { Sangat } \\
\text { Baik }\end{array}$ \\
\hline 9 & I & 4.60 & 4.60 & Sangat Baik & 4.43 & 4.46 & $\begin{array}{l}\text { Sangat } \\
\text { Baik }\end{array}$ \\
\hline 10 & $\mathrm{~J}$ & 4.65 & 4.65 & Sangat Baik & 4.57 & 4.68 & $\begin{array}{l}\text { Sangat } \\
\text { Baik }\end{array}$ \\
\hline & Rata-rata & 4.64 & 4.67 & Sangat Baik & 4.48 & 4.51 & $\begin{array}{c}\text { Sangat } \\
\text { Baik }\end{array}$ \\
\hline
\end{tabular}

Sumber : Data primer (diolah) 
Dari Tabel 5 di atas, dapat dilihat bahwa untuk keseluruhan aspek penyelenggaraan, keseluruhan tingkat kinerja penyelenggaran sudah dinilai oleh peserta dan masuk ke dalam kategori Baik meskipun belum dapat memenuhi tingkat harapan dari peserta. Hal ini dapat dilihat dari perbandingan total rata-rata persepsi /kenyataan dan rata-rata kepentingan menunjukkan rasio di bawah $100 \%$. Di sisi lain, aspek pengajar telah dapat memenuhi harapan dari peserta dimana keseluruhan tingkat kinerja pengajar sudah dinilai oleh peserta dan masuk ke dalam kategori Sangat Baik dengan rasio/perbandingan rata-rata persepsi/kenyataan dan rata-rata kepentingan berada di atas $100 \%$.

\section{Hasil Analisis Importance Performance Analysis (IPA)}

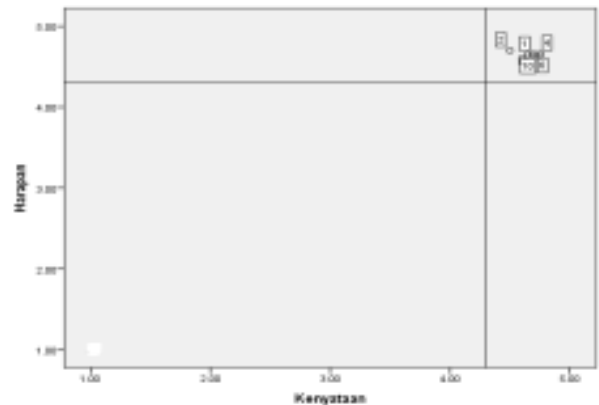

PJJ Pengelolaan Barang Milik Negara Bagi Pengguna
Selanjutnya, data dari Tabel 5 akan digunakan untuk analisis lebih lanjut guna menentukan skala prioritas dalam usaha perbaikan setiap komponen yang ada. Metode yang digunakan adalah metode IPA dengan skala prioritas yang telah disajikan dalam Matriks 1 tentang Matriks Kepentingan Kinerja. Aplikasi yang digunakan dalam menyajikan data grafik adalah aplikasi SPSS versi 22 dengan scatter plot graphic. Garis pembagi antar kuadran dalam Matriks Kepentingan Kinerja ditetapkan pada nilai 4,3 (empat koma tiga) sebagai angka indeks Indikator Kinerja Utama (IKU). Analisis IPA untuk evaluasi pengajar dan evaluasi penyelenggaraan adalah sebagai berikut.

\section{Evaluasi Pengajar}

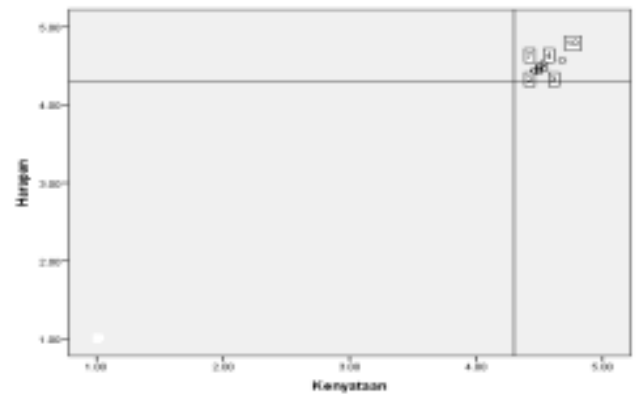

PJJ Kertas Kerja Analisis Wajib Pajak

\section{Gambar1. Grafik IPA Pengajar Sumber : Data primer (diolah)}

Dari gambar 1, dapat dinterpretasikan bahwa semua komponen evaluasi pengajar yang merupakan rata-rata dari skor komponen evaluasi pengajar baik pada PJJ Pengelolaan Barang Milik Negara Bagi Pengguna maupun PJJ Kertas Kerja
Analisis Wajib Pajak seluruhnya masuk ke dalam Kuadran I. Dengan demikian hasil dari evaluasi pengajar sudah sangat baik sehingga perlu dipertahankan. Adapun komponen evaluasi pengajar antara lain: 
Tabel 6. Evaluasi Pengajar

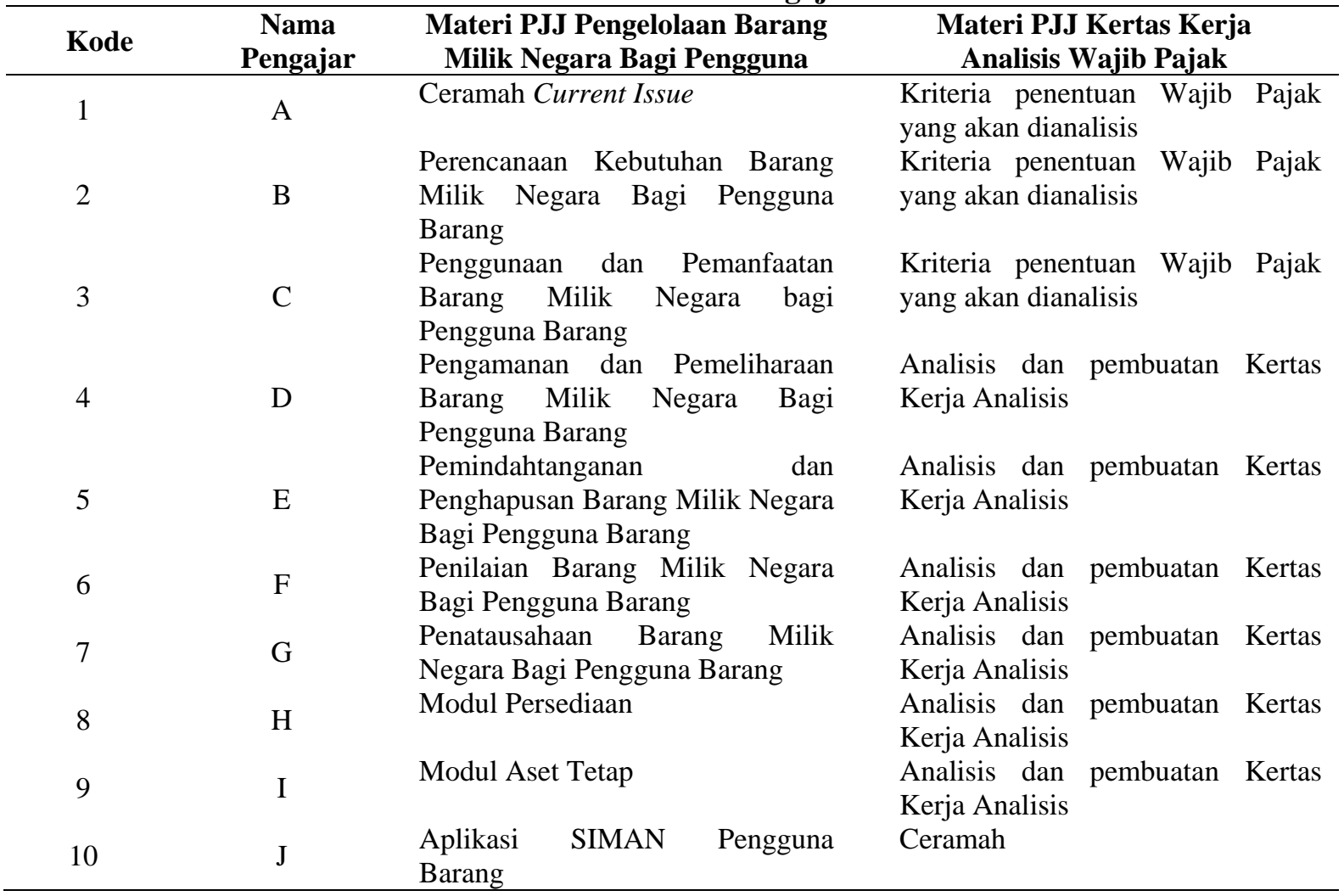

\section{Evaluasi Penyelenggaraan}

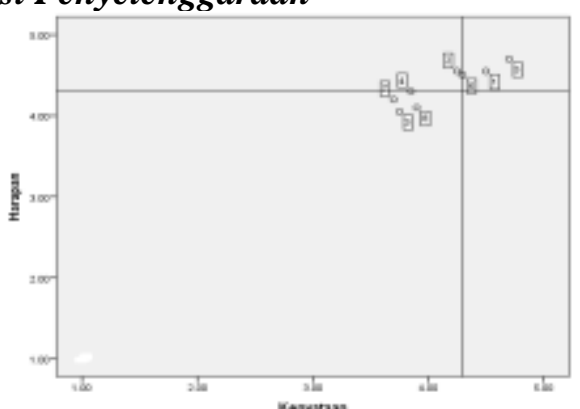

PJJ Pengelolaan Barang Milik Negara Bagi Pengguna

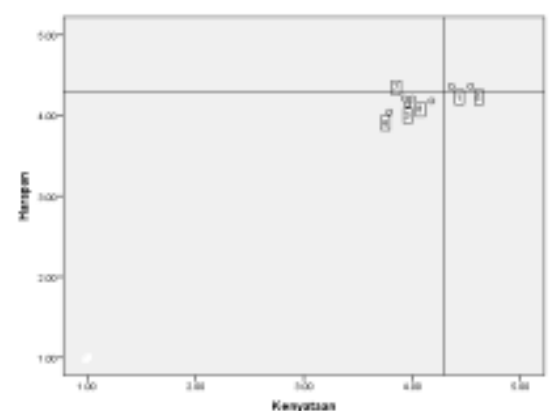

PJJ Kertas Kerja Analisis Wajib Pajak

Gambar 2. Grafik IPA Penyelenggaraan Sumber : Data primer (diolah)

Berdasarkan data yang diperoleh, hasil penyajian sebaran data ke dalam aplikasi SPSS dapat dilihat pada gambar 2. Berdasarkan visualisasi scatter plot pada Grafik 2, dapat dinterpretasikan bahwa semua komponen evaluasi penyelenggaraan untuk PJJ Pengelolaan Barang
Milik Negara Bagi Pengguna masuk ke dalam Kuadran I, II dan III, sedangkan untuk PJJ Kertas Kerja Analisis Wajib Pajak masuk ke dalam Kuadran I dan IV. Adapun komponen evaluasi penyelenggaraan antara lain: 
1. Kesesuaian materi pembelajaran dengan harapan/kebutuhan peserta

2. Bahan ajar mudah dipahami

3. Kesesuaian metode pembelajaran dengan materi Pelatihan Jarak Jauh

4. Ketercukupan waktu penyelenggaraan Pelatihan Jarak Jauh dengan jumlah materi yang diberikan

5. Kesigapan penyelenggara dalam melayani peserta selama proses Pelatihan Jarak Jauh

6. Ketercukupan waktu dalam mengerjakan penugasan, kuis, atau ujian

7. Fasilitas Pelatihan Jarak Jauh mudah diakses

8. Fasilitas Pelatihan Jarak Jauh mudah digunakan

Dengan demikian hasil dari evaluasi penyelenggaraan untuk PJJ Pengelolaan Barang Milik Negara Bagi Pengguna, belum dapat dianggap baik secara keseluruhan. Aspek/komponen kesesuaian materi pembelajaran dengan harapan/kebutuhan peserta, kesigapan penyelenggara dalam melayani peserta selama proses Pelatihan Jarak Jauh, dan ketercukupan waktu dalam mengerjakan penugasan, kuis, atau ujian berada di Kuadran I sehingga perlu dipertahankan. Aspek bahan ajar dan ketercukupan waktu penyelenggaraan Pelatihan Jarak Jauh dengan jumlah materi yang diberikan berada di Kuadran II sehingga perlu diperbaiki. Sementara aspek kesesuaian metode pembelajaran dengan materi Pelatihan Jarak Jauh, fasilitas Pelatihan Jarak Jauh mudah diakses dan fasilitas Pelatihan Jarak Jauh mudah digunakan ada di Kuadran III sehingga tidak menjadi prioritas.
Sedangkan untuk PJJ Kertas Kerja Analisis Wajib Pajak, hasil dari evaluasi penyelenggaraan belum dapat dianggap baik secara keseluruhan. Aspek/komponen kesesuaian materi pembelajaran dengan harapan/kebutuhan peserta dan kesigapan penyelenggara dalam melayani peserta selama proses Pelatihan Jarak Jauh, berada di Kuadran I sehingga perlu dipertahankan. Adapun aspek bahan ajar yang mudah dipahami, kesesuaian metode pembelajaran dengan materi Pelatihan Jarak Jauh, kesesuaian metode pembelajaran dengan materi Pelatihan Jarak Jauh, ketercukupan waktu penyelenggaraan Pelatihan Jarak Jauh dengan jumlah materi yang diberikan, ketercukupan waktu dalam mengerjakan penugasan, kuis, atau ujian, fasilitas pelatihan jarak jauh mudah diakses, dan fasilitas pelatihan jarak jauh mudah digunakan, seluruhnya berada di Kuadran IV sehingga tidak menjadi prioritas (kepentingan/ekspektasi rendah, kinerja rendah).

\section{Analisis Evaluasi Model Kirkpatrick Level 2 (Learning Gain)}

Untuk PJJ Pengelolaan Barang Milik Negara Bagi Pengguna, metode evaluasi pengukuran tingkat pengetahuan dan keterampilan sebagai hasil program pelatihan yang dilakukan adalah dengan melakukan rekapitulasi dan formulasi terhadap nilai kehadiran (p), aktivitas (q) dan ujian per mata pelajaran (r) sehingga diperoleh Nilai Tertimbang $\left(\sum \mathrm{NT}\right)$ dan Nilai Akhir (NA). Ringkasan hasil ujian dapat dilihat dalam Tabel 5 berikut ini.

Tabel 7. Ringkasan Nilai Akhir PJJ Pengelolaan Barang Milik Negara Bagi Pengguna

\begin{tabular}{ccc}
\hline Aspek & $\sum \mathrm{NT}$ & $\mathrm{NA}$ \\
\hline Rata-rata & 80.01 & 80.01 \\
Nilai Tertinggi & 84.40 & 84.40 \\
Nilai Terendah & 60.97 & 60.97 \\
Lulus Predikat Amat Baik & 0 & \\
Lulus Predikat Baik & 18 orang \\
Lulus Predikat Cukup & 1 orang \\
Predikat Minimal Baik & $90 \%$ \\
Tidak Lulus & \multicolumn{2}{c}{1 orang } \\
\hline
\end{tabular}

Sumber: Data primer (diolah) 
Dari Tabel 7 di atas dapat dilihat bahwa sebagian besar peserta lulus dengan predikat Baik yaitu sebanyak 90\%. Peserta yang lulus dengan predikat Cukup sebanyak 1 orang. Peserta yang Tidak Lulus sebanyak 1 orang. Dengan demikian, secara umum dapat dikatakan bahwa peserta telah mendapatkan tambahan ilmu pengetahuan (knowledge) setelah mengikuti PJJ Pengelolaan Barang Milik Negara Bagi Pengguna.

Sementara untuk PJJ Kertas Kerja Analisis Wajib Pajak, metode evaluasi peserta yang dilakukan dalam pelatihan ini adalah dengan melakukan Pre-Test dan Post-Test. Ringkasan hasil ujian dapat dilihat dalam Tabel 8 berikut ini.

Tabel 8. Ringkasan Pre-Test dan Post-Test

\begin{tabular}{ccc}
\hline Aspek & Pre-Test & Post-Test \\
\hline Nilai Tertinggi & 80 & 100 \\
Nilai Terendah & 33 & 67 \\
Rata-rata & 61.5 & 83.2 \\
Nilai yang naik & \multicolumn{3}{c}{ 26 peserta } \\
Nilai yang tetap & \multicolumn{3}{c}{ 3 peserta } \\
Kenaikan tertinggi & \multicolumn{3}{c}{ 47 poin } \\
Rata-rata kenaikan $(\%)$ & 22.07 poin $(42.49 \%)$ \\
\hline
\end{tabular}

Sumber: Data primer (diolah)

Dari Tabel 8 di atas dapat dilihat bahwa sebagian besar peserta memperoleh nilai Post-Test yang naik/meningkat bila dibandingkan dengan nilai Pre-Test. Dari seluruh peserta, peserta yang mendapatkan nilai naik/meningkat adalah sebanyak 26 peserta, sedangkan 3 peserta lainnya memiliki nilai yang tetap. Secara umum dapat dikatakan bahwa peserta telah mendapatkan tambahan ilmu pengetahuan (knowledge) setelah mengikuti PJJ Kertas Kerja Analisis Wajib Pajak.

\section{Kendala dan Masukan}

Meskipun secara umum hasil evaluasi menunjukkan hasil yang baik, masih tampak adanya beberapa kendala yang dihadapi oleh alumni dalam mengikuti pelatihan. Kendalakendala tersebut perlu mendapatkan perhatian guna meningkatkan kualitas layanan dan efektivitas pelatihan.
Beradasarkan hasil survei dan wawancara, pada aspek penyelenggaraan, baik pada PJJ Pengelolaan Barang Milik Negara Bagi Pengguna maupun PJJ Kertas Kerja Analisis Wajib Pajak, peserta pada umumnya mengeluhkan tentang kualitas jaringan internet yang tidak memadai di beberapa daerah. Selain itu, keluhan yang muncul juga terkait durasi waktu belajar yang relatif kurang. Sementara itu pada aspek pengajar, baik pada PJJ Pengelolaan Barang Milik Negara Bagi Pengguna maupun PJJ Kertas Kerja Analisis Wajib Pajak, pada umumnya peserta memberi masukan kiranya para pengajar dapat memperbanyak studi kasus dan mengangkat isuisu terkini dalam pengananan masalah terkait materi pelatihan.

Secara ringkas, kendala dan masukan dari para peserta terhadap pelatihan, baik pada aspek penyelenggaraan maupun pengajar, dapat dilihat pada Tabel 9 berikut. 
Tabel 9. Kendala dan Masukan

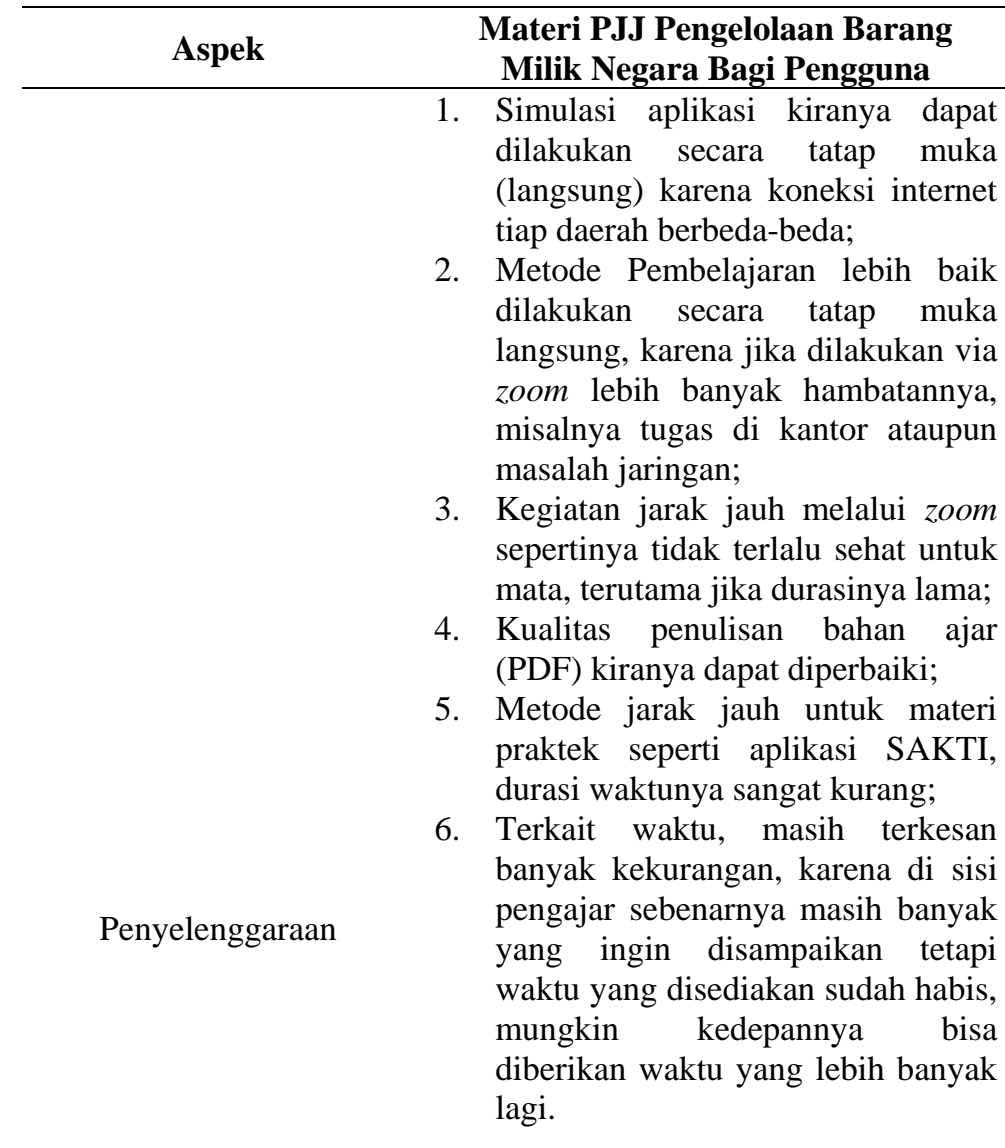

Materi PJJ Kertas Kerja Analisis

Wajib Pajak

1. Terkendala dengan jaringan yang tidak merata di seluruh daerah.

2. Sebaiknya peserta diklat diusulkan untuk WFH sehingga tidak terganggu dengan pekerjaan lain.

3. Pelatihan seperti ini sebaiknya dilakukan dengan tatap muka.

4. Biaya akses kuota internet kiranya dapat disubsidi oleh penyelenggara apalagi anggaran makan minum yang biasanya ada sekarang tidak ada karena sifatnya PJJ.

5. Mungkin dapat mempertimbangkan penggunaan aplikasi selain zoom seperti CloudX/Microsoft Teams, WebEx, atau Umeetme yang didukung oleh paket ketenangan conference Telkomsel agar dapat memudahkan dan meringankan biaya bagi yang tidak mendapatkan akses Wifi.

6. Metode PJJ saja yang kurang aplikatif karena diskusi kurang berjalan dengan baik.

7. Metode pembelajaran menggunakan PJJ dengan tatap muka via zoom jangan dilakukan sepanjang hari, mungkin setengah hari kemudian setengah harinya diberikan tugas, kemudian disesuaikan dengan waktu pembelajaran karena memperhatikan teman lain yang terdapat di daerah yang jauh mungkin susah sinyal atau mungkin tidak menggunakan wifi dan menggunakan kuota pribadi.

8. Perbedaan waktu pun juga harus disesuaikan khususnya bagi temanteman wilayah bagian timur agar tidak terlalu malam. $\begin{array}{llr}\text { 1. Dalam } & \text { beberapa materi } \\ \text { pembelajaran, materi } & \text { yg }\end{array}$ disampaikan lebih banyak berdasar Pengajar handbook dan tidak berdasar studi kasus, sehingga peserta kurang bisa memahami berbagai macam studi kasus dari setiap materi shg bisa dipahami;
1. Soal latihan/kasus kiranya dapat diberikan sehari sebelum presentasi sehingga ada waktu lebih untuk membuat analisis

2. Alangkah baiknya dalam penyiapan soal/kuis sudah disiapkan Kertas Kerja Analisis berdasarkan pihak panitia/pengajar agar peserta 
Jurnal PAJAR (Pendidikan dan Pengajaran)

Volume 4 Nomor 6 November 2020 | ISSN Cetak : 2580 - 8435 | ISSN Online : 2614 - 1337

DOI : http://dx.doi.org/10.33578/pjr.v4i6.8131

2. Pengajar cukup baik dalam menyampaikan materi, tetapi diharapkan untuk meminimalisir tugas yang diberikan saat pembelajaran jarak jauh, mengingat masih adanya tugas yang harus dikerjakan di kantor;

3. Memperbanyak isu-isu dan penanganan masalah terkait Barang Milik Negara, berdasarkan aturan yang berlaku dan runtut, sehingga permasalahan masing-masing satker dapat dilakukan;

4. Untuk materi aplikasi semoga mendapat waktu lebih banyak lagi. Kalau perlu jadwalnya tatap muka semua (khusus aplikasi). pelatihan dapat mempelajari Kertas

Kerja Analisis yang benar berdasarkan Pengajar yang telah berpengalaman.

3. Agar sebelum masuk ke latihan soal analisa, dipersiapkan terlebih dahulu format yang dibutuhkan dan soal yang disajikan mudah diolah sehingga peserta tidak menghabiskan banyak waktu untuk membuat format tetapi fokus ke analisa

4. Kalau bisa, kunci jawaban dari 4 soal pelatihan kemarin dapat diberikan sebagai bahan evaluasi buat peserta terkait analisisnya.

5. Durasi waktu kadang terlewat.

6. Masukan terkait pengajar, agar ada pengajar yang merupakan Account Representative yang masih aktif dan berpengalaman di berbagai kantor, baik itu pratama, madya, dan khusus agar ilmu dan pengalaman yang dibagikan menjadi lebih banyak, mendetail, dan komprehensif.

7. Lebih agresif lagi untuk menghidupkan suasana diskusi.

8. Agar para pengajar terbuka untuk diajak diskusi pascapelatihan ini.

9. Perlu ditambahkan waktu jamlat sehingga diskusi/sharing bisa lebih banyak waktu.

Sumber : Data primer (diolah)

\section{SIMPULAN DAN REKOMENDASI}

Berdasarkan analisis dan pembahasan, dapat ditarik beberapa kesimpulan sebagai berikut: 1) Keseluruhan aspek penyelenggaraan sudah dinilai oleh peserta dan masuk ke dalam kategori Baik meskipun belum dapat memenuhi tingkat harapan dari peserta. Hal ini dapat dilihat dari perbandingan total rata-rata persepsi/ kenyataan dan rata-rata kepentingan yang menunjukkan rasio di bawah $100 \%$. Di sisi lain, aspek pengajar telah dapat memenuhi harapan dari peserta dimana keseluruhan tingkat kinerja pengajar sudah dinilai oleh peserta dan masuk ke dalam kategori Sangat Baik; 2) Berdasarkan metode IPA, hasil evaluasi penyelenggaraan menunjukkan bahwa semua komponen evaluasi penyelenggaraan untuk PJJ Pengelolaan Barang Milik Negara Bagi Pengguna masuk ke dalam Kuadran I, II dan III, sedangkan untuk PJJ Kertas Kerja Analisis Wajib Pajak masuk ke dalam Kuadran I dan IV. Sedangkan hasil evaluasi pengajar menunjukkan bahwa semua komponen evaluasi pengajar yang merupakan rata-rata dari skor komponen evaluasi pengajar baik pada PJJ Pengelolaan Barang Milik Negara Bagi Pengguna maupun PJJ Kertas Kerja Analisis Wajib Pajak seluruhnya masuk ke dalam Kuadran I sehingga perlu dipertahankan; 3) Hasil analisis evaluasi 
pada Level 2 (Learning Gain), baik pada PJJ Pengelolaan Barang Milik Negara Bagi Pengguna maupun PJJ Kertas Kerja Analisis Wajib Pajak, menunjukkan bahwa sebagian besar peserta lulus dengan predikat Baik dan mendapatkan nilai naik/meningkat. Dengan demikian, secara umum dapat dikatakan bahwa peserta telah mendapatkan tambahan ilmu pengetahuan (knowledge) setelah mengikuti pelatihan; 4) Meskipun secara umum hasil evaluasi menunjukkan hasil yang baik, masih tampak adanya beberapa kendala yang dihadapi oleh alumni selama mengikuti pelatihan. Pada aspek penyelenggaraan, baik pada PJJ Pengelolaan Barang Milik Negara Bagi Pengguna maupun PJJ Kertas Kerja Analisis Wajib Pajak, peserta pada umumnya mengeluhkan kualitas jaringan internet yang tidak memadai di beberapa daerah. Sementara itu pada aspek pengajar, baik pada PJJ Pengelolaan Barang Milik Negara Bagi Pengguna maupun PJJ Kertas Kerja Analisis Wajib Pajak, pada umumnya peserta memberi masukan kiranya para pengajar dapat memperbanyak studi kasus dan mengangkat isuisu terkini dalam penanganan masalah terkait materi pelatihan.

Selanjutnya, berdasarkan hasil pembahasan dan kesimpulan di atas diperlukan upaya bersama untuk mewujudkan konsep link and match antara pembelajaran, pengelolaan pengetahuan dan penerapan nilai-nilai dengan target kinerja pada unit kerja di Kementerian Keuangan terkait dengan pelatihan. Beberapa saran/rekomendasi yang dapat diberikan antara lain: 1) Perlu penambahan jamlat, materi studi kasus dan praktik khususnya pada materi pelatihan aplikasi yang digunakan dalam tugas. 2) Perlu penambahan durasi pembelajaran atau frekuensi pelatihan agar kompetensi dapat lebih ditingkatkan. 3) Perlu penguatan koordinasi dengan instansi terkait dalam hal penugasan peserta pelatihan agar peserta pelatihan yang diikutsertakan memang dipersiapkan untuk melakukan tugas baik sebagai pengelola BMN maupun sebagai Account Representative pada kantor pelayanan pajak.

\section{DAFTAR PUSTAKA}

Arikunto, S., \& Jabar, C.S.A. (2008). Evaluasi Program Pendidikan. Bumi Aksara.

BPPK. (2014). Peraturan Kepala Badan dan Pelatihan Keuangan Nomor PER001/PP/2014 tentang Pedoman Evaluasi dan Rekomendasi Diklat di Lingkungan Kementerian Keuangan.

BPPK. (2017). Peraturan Kepala BPPK Nomor PER-5/PP/2017 tentang Pedoman Evaluasi Pembelajaran di Lingkungan Kementerian Keuangan.

BPPK. (2020). Keputusan Kepala BPPK Nomor $K E P-82 / P P / 2020$ tentang Panduan Penyelenggaraan Pelatihan Jarak Jauh (Distance Learning) di Lingkungan Badan Pendidikan dan Pelatihan Keuangan.

Hartono, J. 2011. Metodologi Penelitian Bisnis: Salah Kaprah dan Pengalamanpengalaman. Yogyakarta: BPFE.

Hayadin, H. (2012). Penelitian Evaluasi Penyelenggaraan Diklat Jarak Jauh (DJJ). EDUKASI: Jurnal Penelitian Pendidikan Agama dan Keagamaan, 10(1).

Iskandar, A. (2019). Evaluasi Diklat ASN Model Kirkpatrick (Studi Kasus Pelatihan Effective Negotiation Skill Balai Diklat Keuangan Makassar). Jurnal Pendidikan, 20(1), 18-39.

Iskandar, A., \& Amriani, T. N. (2019). Implementasi evaluasi pasca pembelajaran model Kirkpatrick level 1,2 dan 3 pada pelatihan bendahara pengeluaran di Balai Diklat Keuangan Makassar. Wiyata Dharma: Jurnal Penelitian dan Evaluasi Pendidikan, 7(2).

Kirkpatrick, D. L., \& Kirkpatrick, J.D. (2008). Evaluating Training Programs. San Francisco: Berrett-Koehler Publishers,Inc.

Narayana, I. W. G. (2016). Analisis Terhadap Hasil Penggunaan Metode Pembelajaran Synchronous dan

Asynchronous. Semnasteknomedia Online, 4(1), 1-4.

Sari, N. L. (2020). Pelatihan Model Pembelajaran Jarak Jauh Berbasis Google Form Sebagai 
Jurnal PAJAR (Pendidikan dan Pengajaran)

Volume 4 Nomor 6 November 2020 | ISSN Cetak : 2580 - 8435 | ISSN Online : 2614 - 1337

DOI : http://dx.doi.org/10.33578/pjr.v4i6.8131

Media Pembela. KOMMAS: Jurnal

Pengabdian Kepada Masyarakat, 1(2).

Sarwono, J. (2006). Metode Penelitian,

Kuantitatif dan Kualitatif. Yogyakarta:

Graha Ilmu.

Septian, F. (2020). Pelatihan Pendidikan Jarak

Jauh (PJJ) Berbantuan Media Sosial

Edmodo.com bagi Guru SMP Terbuka

Sawangan Depok. JAMAIKA: Jurnal Abdi Masyarakat, 1(2), 60-68.

Sugiyono. (2005). Metode Penelitian Bisnis.

Bandung: Alfabeta. 